\title{
The progression of gliomas is associated with cancer stem cell phenotype
}

\author{
DOO-SIK KONG ${ }^{1}$, MI HYUN KIM ${ }^{1}$, WOONG-YANG PARK ${ }^{2}$, YEON-LIM SUH $^{3}$ \\ JUNG-IL LEE $^{1}$, KWAN PARK ${ }^{1}$, JONG HYUN KIM ${ }^{1}$ and DO-HYUN NAM ${ }^{1}$
}

\begin{abstract}
${ }^{1}$ Department of Neurosurgery, Samsung Medical Center, Sungkyunkwan University School of Medicine;
${ }^{2}$ Department of Biochemistry, Seoul National University, School of Medicine; ${ }^{3}$ Department of Pathology,

Samsung Medical Center, Sungkyunkwan University School of Medicine, Seoul, Korea
\end{abstract}

Received September 27, 2007; Accepted November 9, 2007

\begin{abstract}
Since cancer stem cells in brain tumors were introduced, there have been few explanations regarding the role of cancer stem cells in the progression of glioma. Here, we investigated their major molecular changes in tumor progression in relation to the stem cell subpopulation. Using 12 surgical specimens of gliomatosis cerebri (GC) in the early and advanced stages, we measured the expression of a panel of cell proliferation, microvessel density, microvessel areas, angiogenic factors and their associated receptors. In addition, expression of neural stem cell markers and associated cytokines were examined in tumor tissues by quantitative realtime RT-PCR. Comparing the biological characteristics between the initial infiltrating lesions $(n=7)$ and progressed lesions $(n=5)$, Sox 2 and Musashi-1 were expressed in the tumor tissue at an early and a progressed state. Contrary to the early infiltrative phase representing angiogenesisindependent growth, GC with progression showed that nestin $(+)$, PCNA (+) cells and total vessel area (angioectasia) were markedly increased with a higher expression of proangiogenic molecules and their receptors. These results suggest that tumor progression is mediated by cancer stem cells and cross-talk of cancer stem cells along with their environment and are closely associated with angiogenesis-dependent progression and -independent growth.
\end{abstract}

\section{Introduction}

Recent studies have identified that tumor cell subpopulations might be responsible for tumor initiation (1-3), though little is

Correspondence to: Dr Do-Hyun Nam, Department of Neurosurgery, Samsung Medical Center, Sungkyunkwan University School of Medicine, 50 Ilwon-dong, Kangnam-gu, Seoul 135-710, Korea

E-mail: nsnam@skku.edu

Abbreviations: GC, gliomatosis cerebri; MR, magnetic resonance

Key words: gliomatosis cerebri, tumor progression, cancer stem cell known about the mechanism that contributes to the acceleration of tumor progression (4). In general, tumor progression is known to require angiogenesis (4-6). Tumor progression, so-called cancer dedifferentiation is accelerated by unknown mechanisms giving rise to clinical deterioration. Once it begins to progress, tumor progression leads to robust proliferation with an emerging enhancement and has eventually shortened the survival below one or two years.

Gliomatosis cerebri (GC) is a rare variant of glioma, characterized by a highly diffuse infiltrative pattern with the preservation of the normal architecture (7-11), while glioblastomas (GBMs) are the most common brain tumor and highly vascular tumor. GC is considered to be a lesion of intermediate malignancy in the progression of diffuse astrocytoma to GBMs. These tumors coopt the host vasculature without signs of angiogenesis and are present as an invasive growth. GC shares common characteristics with neural stem cells, in that they show migratory behavior, diversity of progeny and have a proliferative potential. However, serial follow-up images revealed that new enhancement, mass formation and necrotic portion emerged, which clinically implied that an initial angiogenesisindependent growth pattern had shifted into an angiogenesisdependent phenotype.

Here, in an attempt to determine whether cancer stem cells are the driving force in tumor progression, we investigated their major phenotypic changes in tumor progression in relation to the stem cell subpopulation.

\section{Materials and methods}

Patients and specimen collection. Among the 45 patients who were diagnosed with GC at our institute between January 1999 and December 2004, we analyzed the clinical factors associated with tumor progression and the overall survival. We were able to obtain adequate tumor tissues from 12 tissue specimens after cytoreductive surgery among the cohort. These archival histopathological materials yielded tumor tissue of sufficient quality in 7 GCs at the early stage and 5 GCs following rapid progression. Cell proliferation, microvessel density and microvessel areas were analyzed by immunohistochemistry (PCNA and CD31). In an attempt to determine a potential mechanism for tumor progression, we 
Table I. Immunohistochemistry findings at the pre- and post-progression stages in gliomatosis cerebri.

\begin{tabular}{|c|c|c|c|c|c|c|c|c|c|c|c|c|c|}
\hline & No. & Nestin & $\mathrm{O} 4$ & GFAP & CD133 & Sox 2 & PCNA & CD31 & VEGF & PDGFA & PDGFB & $\begin{array}{c}\text { PDGFR } \\
-\alpha\end{array}$ & $\begin{array}{c}\text { PDGFR } \\
-\beta\end{array}$ \\
\hline \multirow{6}{*}{ Early stage } & $\mathrm{T} 2$ & +++ & +++ & ++ & ++ & + & +++ & + & +++ & +++ & ++ & 0 & + \\
\hline & $\mathrm{T} 3$ & +++ & ++ & +++ & ND & + & +++ & +++ & +++ & + & +++ & + & 0 \\
\hline & $\mathrm{T} 4$ & + & ++ & +++ & ++ & + & ++ & 0 & +++ & +++ & +++ & ++ & 0 \\
\hline & $\mathrm{T} 5$ & 0 & + & +++ & ND & + & +++ & + & + & +++ & +++ & +++ & 0 \\
\hline & T6 & ++ & ++ & +++ & ND & ND & ++ & + & + & ++ & ++ & 0 & 0 \\
\hline & $\mathrm{T} 7$ & 0 & 0 & +++ & + & ND & +++ & 0 & +++ & +++ & +++ & ++ & + \\
\hline \multirow[t]{4}{*}{ Advanced stage } & $\mathrm{T} 8$ & +++ & +++ & +++ & ND & +++ & ++ & +++ & +++ & +++ & +++ & +++ & +++ \\
\hline & T9 & +++ & ++ & +++ & +++ & +++ & +++ & +++ & +++ & +++ & +++ & +++ & +++ \\
\hline & $\mathrm{T} 10$ & +++ & +++ & +++ & +++ & +++ & ++ & +++ & +++ & +++ & +++ & +++ & +++ \\
\hline & T12 & +++ & +++ & +++ & +++ & +++ & ++ & +++ & ++ & +++ & +++ & +++ & +++ \\
\hline
\end{tabular}

Positive tumor cells were determined and scored in a semiquantitative fashion: 0 , no positive cells; + , weak immunoexpression; ++ , moderate immunoexpression; +++, strong immunoexpression; ND, not done.

measured the expression of a panel of angiogenic factors and their receptors (VEGF, EGF, bFGF, PDGF and their receptors).

Immunohistochemical study. A representative paraffin block of formalin-fixed tumor tissues from 12 patients was selected. Brain tumor tissues were fixed in $4 \%$ paraformaldehyde and were paraffin-embedded. Sections (4- $\mu \mathrm{m}$ thick) were deparaffinized with xylene and rehydrated through a series of graded alcohols. Endogenous peroxidase activity was blocked by incubation $\left(15 \mathrm{~min}\right.$ ) in $0.3 \% \mathrm{H}_{2} \mathrm{O}_{2}$ in methanol. Slides were stained with a primary antibody overnight at $4^{\circ} \mathrm{C}$. We obtained primary antibodies of human nestin from Abcam (1:1200, ab5968), human CD133 from Miltenyi biotec (1:5, W6B3C1), PCNA (anti-PCNA, PC-10, mouse IgG), GFAP, Platelet-derived growth factor (PDGF)-A, PDGF-B, PDGFR- $\alpha$ and PDGFR- $\beta$, from Santa Cruz Biotechnology, Inc. (1:100-2000), human O4 from Chemicon (1:50, MAB345), $\alpha$-smooth muscle actin (ASMA) from Dako (1:30, M 0823 and 1:100, U7033). Appropriate secondary biotinconjugated antibody was applied for $1 \mathrm{~h}$ at room temperature. Negative controls included omission of the primary antibody and its substitution with an irrelevant mouse monoclonal antibody. DAB (3,3-diaminobenzidine hydrochloride containing $0.08 \%$ hydrogen peroxide) was used as a chromogen to visualize the peroxidase activity. For double immunofluorescent visualization, secondary antibodies Alexa 488 (red-colored) and Alexa 594 (green-colored) (Jackson ImmunoResearch) were used. In representative areas of the tumor tissue, positive tumor cells were determined and scored in a semiquantitative fashion: -, no positive cells; + , weak immunoexpression; ++, moderate immunoexpression; +++, strong immunoexpression.

$R T-P C R$ and quantitative real-time $R T-P C R$. The first strand cDNA was synthesized from $1 \mu \mathrm{g}$ of total RNA using reverse transcriptase and $1 \mu \mathrm{M}$ of oligo-dT primers like PROM1 (sense, CTG GGG CTG CTG TTT ATT ATT CTG; antisense,
ACG CCT TGT CCT TGG TAG TGT TG), SOX2 (sense, CAG GAG AAC CCC AAG ATG C; antisense, GCA GCC GCT TAG CCT CG), NES (sense, TGG CTC AGA GGA AGA GTC TGA; antisense, TCC CCC ATT CAC ATG CTG TGA), MSI1 (sense, GCC CAA GAT GGT GAC TCG; antisense, ATG GCG TCG TCC ACC TTC), and GAPDH (sense, GAA GGT GAA GGT CGG AGT C; antisense, GAA GAT GGT GAT GGG ATT TC). Each cDNA sample was amplified by using specific primers. Specific bands corresponding to the estimated sizes were analyzed after agarose gel electrophoresis. To quantify the amount of transcripts, real-time RT-PCR based on the MyQ system (Bio-Rad, CA) was performed as described in the manufacturer's recommendations. The relative amount of each transcript was normalized with the level of GAPDH. The calibrator sample was represented by a pool of normal mesenchymal tissues (muscles, vessels, adipose tissue and nerves).

Angiogenesis and cell proliferation properties. Immunohistochemistry for CD31 was performed on freshly cut frozen tissue. These slides were fixed in cold acetone for $10 \mathrm{~min}$ and did not require antigen retrieval. The primary antibody used was anti-CD31 (platelet/endothelial cell adhesion molecule-1, rat IgG; PharMingen). To quantify microvessel density and microvessel area, 10 random $0.159-\mathrm{mm}^{2}$ fields at x100 final magnification were examined for each tumor. The number of microvessels per field were counted by two investigators in a blinded fashion and the sectional area of microvascular lumen per field was measured with the same method. A single microvessel was defined as a discrete cluster or single cell stained positive for CD31 and the presence of a lumen was required for scoring as a microvessel.

\section{Results}

Based on the analysis of the patients' clinical data and their MR images, we found that the enhancing lesion eventually 


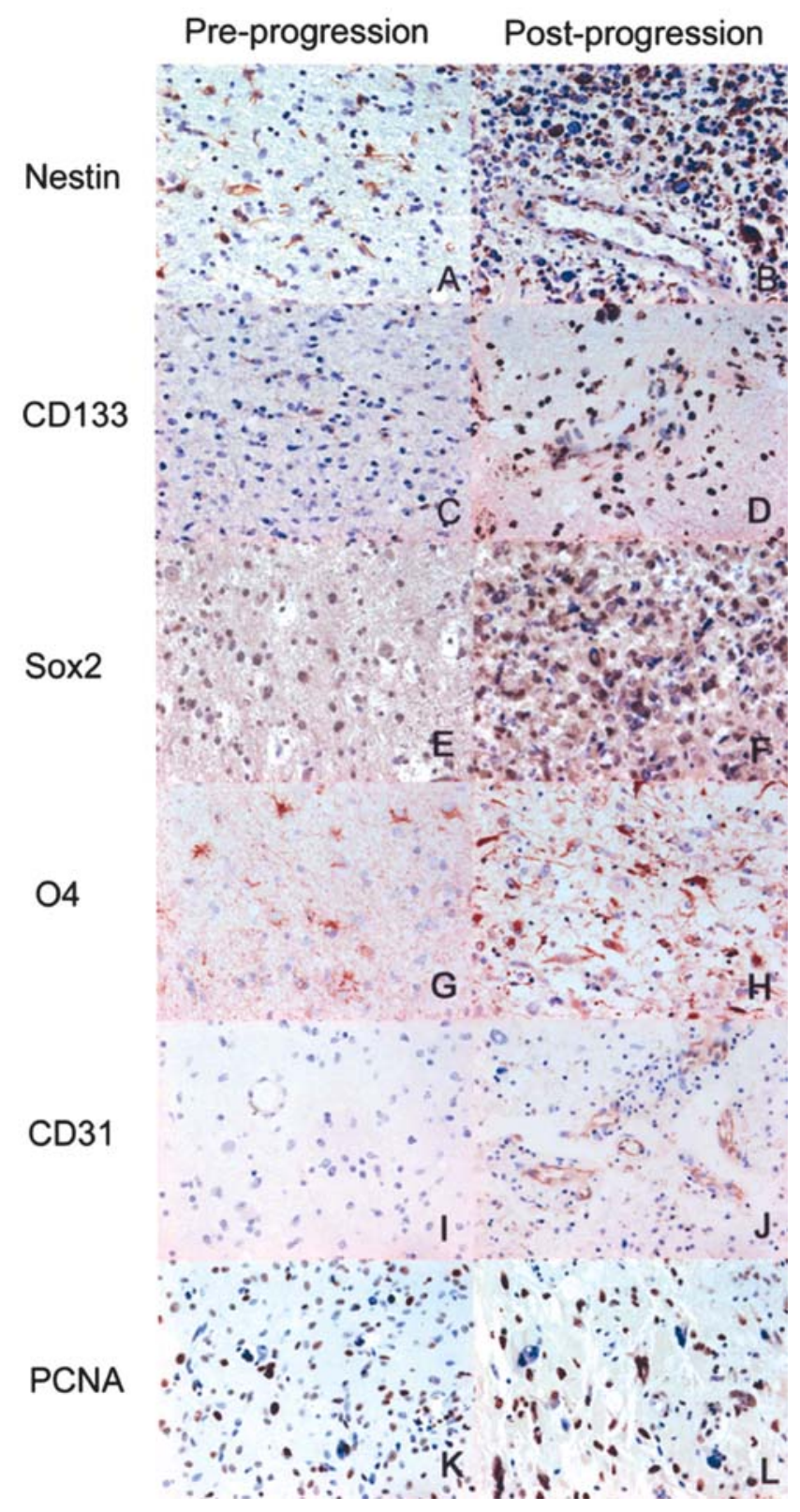

Figure 1. Protein expression of neural stem cell markers assessed by immunohistochemistry (magnification, $x$ 400) in the early and advanced stages in gliomatosis cerebri. Positive staining is indicated by the presence of a brown color (DAB stain). Left, early stage. Right, advanced stage. Compared with the early stage, expressions of nestin, CD133, O4 and Sox2 are increased at the advanced stage. Additionally, on the CD31 and PCNA staining, an angioectatic change of blood vessels and increased cell proliferation are observed after progression.

emerged in the advanced stage of GC and demonstrated unresponsiveness to the chemo-irradiation (unpublished).

Tumor progression and angiogenesis. Early infiltrative tumor tissues (early stage, $n=7$ ) demonstrated a histologically lowgrade and well-differentiated state without enhancement, whereas late advanced tumor tissues with an enhancing lesion (advanced stage, $n=5$ ) exhibited progressed, high-grade and undifferentiated tumor cells with enhancement. With regard to cellular proliferation, post-progressive tumor tissues showed a marked increase of PCNA (+) cells, compared with pre-progressive tumor tissues. This implied that the post- progressive tumor was at a more advanced stage in the tumor progression. In terms of angiogenesis, the measurement of microvascular density revealed no definite difference between the stages. However, the microvessel area was markedly increased in the advanced stage of the tumor, which implied that angioectasis had developed in accordance with the tumor progression. Furthermore, after tumor progression, PDGF receptor $\alpha$ and $\beta$-positive cells were increasingly found around the angioectactic blood vessels. It indicated that tumor phenotypes changed from non-angiogenesis-dependent growth into an angiogenesis-dependent growth as tumors progressed.

Expression of stem cell markers. To further characterize the cellular composition of the tumors, we investigated the stem cell properties by an immunohistochemical study and realtime RT-PCR. Immunoexpression of a variety of markers is summarized in Table I (EGF and bFGF data are not shown). When comparing the biological characters between the before and after progression stages, Sox 2 and Musashi-1 were equivocally expressed in both stages. However, nestin, one of the neural progenitor cell markers, was more extensively expressed in the advanced stage (Fig. 1). Quantitative realtime PCR indicated that tumor cells also exhibited a marked increase of stem cell markers such as nestin and CD133 in the advanced stage, while they revealed persistence of expression of Sox 2 and Musashi-1 (Fig. 2). The increase of CD133 expression was more frequently observed in the advanced stage rather than in the early stage of the tumor (Fig. 3). However, CD133 expression could not be accurately evaluated by real-time PCR, since its expression rate was too low in the two stages of tissues (data were not shown). Contrary to the early stage of angiogenesis-independent growth, tumor tissues in the advanced stage showed that Sox2, nestin and PDGFR- positive cells were prominent around the angioectatic vessels associated with a higher expression of proangiogenic molecules and their receptors (Fig. 3).

\section{Discussion}

Gliomatosis (GC) is a good model to explain the type of mechanism contributing to tumor progression. Glioblastomas (GBMs) are highly lethal cancers dependent on angiogenesis. Previous studies have suggested that although tumor cells initially coopt normal cerebral vessels, they subsequently require angiogenesis. GBMs may arise from the malignant progression of low-grade gliomas - referred to as secondary GBMs. However, little is known regarding the mechanism that contributes to the acceleration of tumor progression. In an attempt to comprehend the mechanism, several authors have identified that high-grade features of GC caused by tumor progression are driven by similar molecular genetic alterations which are found in secondary glioblastoma (11-13). Recently, Bao et al suggested the possibility that tumor progression with angiogenesis is mediated by cancer stem cells (14).

It has been reported that GC shows angiogenesisindependent tumor growth as a form of cooption of normal cerebral vessels $(9,15-22)$. However, malignant progression 

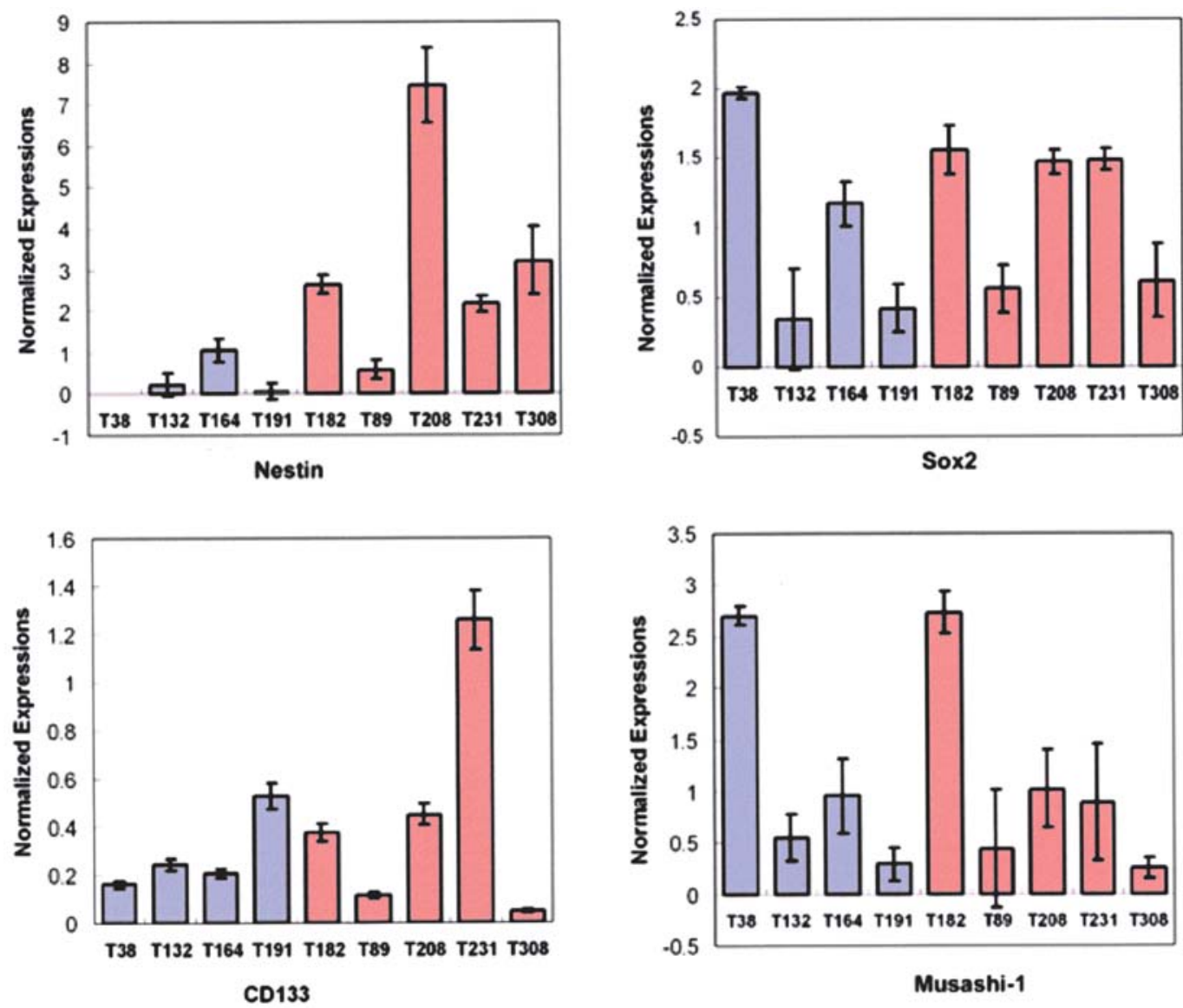

Figure 2. Differential expression levels of neural stem markers measured by quantitative real-time RT-PCR. Blue bars, early stage; red bars, advanced stage. Comparison of changes in the expression levels of four stem cell markers between 4 pre-progression samples and 5 post-progression samples.

PDGF A

Pre-progression
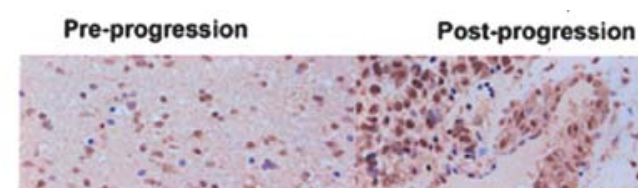

$\because 40 \%$

Hosi

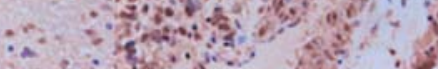

PDGF B

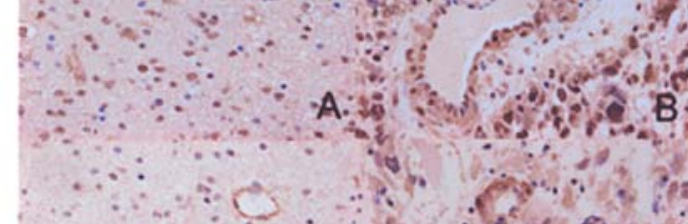

PDGFR- $\beta$

PDGFR-a

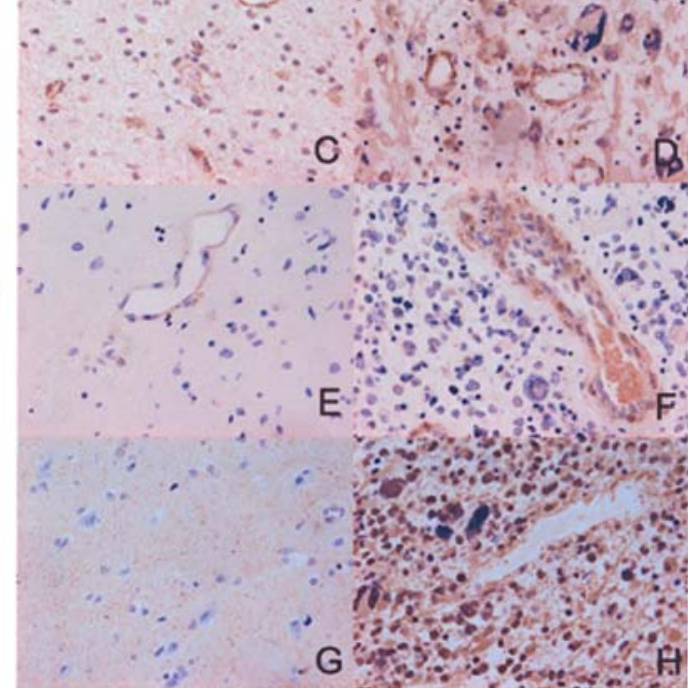

Figure 3. Protein expression of PDGFs and their receptors detected by immunohistochemistry (magnification, $x$ 400). with angiogenesis requires only one to two years from the initial diagnosis of the pre-progressive lesion. In addition, GC in the early stage can be regarded as a pre-malignant lesion in that almost of all GCs eventually have a malignant transformation, even if GC in the early stage does not accompany neo-angiogenesis. It is comparable with only some of the low-grade gliomas, which experience the malignant transformation and require many years to evolve into the secondary glioblastoma. In this aspect, GC tissues can therefore be a good model in investigating the putatively independent role of cancer stem cells during tumor progression.

Suggestive role of the cancer stem cell in tumor progression. GC in the early stage, is histologically characterized by varying degrees of differentiation. GC and neural stem cells harbor common features of extensive brain parenchymal migratory infiltration, cell division and the potential for full or partial differentiation properties $(23,24)$. It is worth noting that tumor cells increasingly express proangiogenic molecules and stem cell markers in the advanced stage. It is implied that cancer stem cells may have a contributing role in the malignant progression. We found that the newly formed vessel releases a signal that leads to the induction of PDGFR$\beta$-positive pericyte progenitors from surrounding undifferentiated mesenchyme, while PDGFR- $\beta$-positive pericyte progenitors are essentially lacking in normal brain tissue $(25,26)$. Recent studies reported that tumor formation can be 
induced by the activation of receptor tyrosine kinases such as PDGF receptors (26-28). In this study, a high expression of PDGF receptors on the paraffin section of post-progressive tumor showed evidence that tumor progression was initiated by an early progenitor or stem cells (20).

In conclusion, findings that tumor cells overexpressed Sox2, nestin and PDGFR along the angioectatic vessels suggest that tumor progression can be mediated by cancer stem cells and cross-talk of cancer stem cells. Along with their environment, they are closely associated with angiogenesisdependent progression and angiogenesis-independent growth.

\section{Acknowledgements}

This study was supported by the Korean Science and Engineering Foundation (KOSEF) grant funded by the Korean government (MOST) (\#M10641000104-060N410010410) and Samsung Biomedical Research Institute (SBRI) (C-A7-410-1).

\section{References}

1. Galli R, Binda E, Orfanelli U, Cipelletti B, Gritti A, De Vitis S, Fiocco R, Foroni C, Dimeco F and Vescovi A: Isolation and characterization of tumorigenic, stem-like neural precursors from human glioblastoma. Cancer Res 64: 7011-7021, 2004.

2. Reya T, Morrison SJ, Clarke MF and Weissman IL: Stem cells, cancer, and cancer stem cells. Nature 414: 105-111, 2001.

3. Singh SK, Clarke ID, Terasaki M, Bonn VE, Hawkins C, Squire J and Dirks PB: Identification of a cancer stem cell in human brain tumors. Cancer Res 63: 5821-5828, 2003.

4. Brabletz T, Jung A, Spaderna S, Hlubek F and Kirchner T: Opinion: migrating cancer stem cells - an integrated concept of malignant tumour progression. Nat Rev Cancer 5: 744-749, 2005.

5. Folkman J: Tumor angiogenesis: therapeutic implications. N Engl J Med 285: 1182-1186, 1971

6. Sakariassen PO, Prestegarden L, Wang J, Skaftnesmo KO, Mahesparan R, Molthoff C, Sminia P, Sundlisaeter E, Misra A, Tysnes BB, Chekenya M, Peters H, Lende G, Kalland KH, Oyan AM, Petersen K, Jonassen I, van der Kogel A, Feuerstein BG, Terzis AJ, Bjerkvig $\mathrm{R}$ and Enger PO: Angiogenesis-independent tumor growth mediated by stem-like cancer cells. Proc Natl Acad Sci USA 103: 16466-16471, 2006.

7. Couch JR and Weiss SA: Gliomatosis cerebri. Report of four cases and review of the literature. Neurology 24: 504-511, 1974.

8. del Carpio-O'Donovan R, Korah I, Salazar A and Melancon D: Gliomatosis cerebri. Radiology 198: 831-835, 1996.

9. Artigas J, Cervos-Navarro J, Iglesias JR and Ebhardt G: Gliomatosis cerebri: clinical and histological findings. Clin Neuropathol 4: 135-148, 1985.

10. Choi D, Schulz U and Seex K: Gliomatosis cerebri: a brain tumour which is too difficult to treat? Scott Med J 43: 84-86, 1998.

11. Mawrin C: Molecular genetic alterations in gliomatosis cerebri: what can we learn about the origin and course of the disease? Acta Neuropathol (Berl) 110: 527-536, 2005.
12. Kleihues $\mathrm{P}$ and Ohgaki H: Primary and secondary glioblastomas: from concept to clinical diagnosis. Neurooncology 1: 44-51, 1999.

13. Kirches E, Mawrin C, Schneider-Stock R, Krause G, Scherlach C and Dietzmann K: Mitochondrial DNA as a clonal tumor cell marker: gliomatosis cerebri. J Neurooncol 61: 1-5, 2003.

14. Bao S, Wu Q, Sathornsumetee S, Hao Y, Li Z, Hjelmeland AB, Shi Q, McLendon RE, Bigner DD and Rich JN: Stem cell-like glioma cells promote tumor angiogenesis through vascular endothelial growth factor. Cancer Res 66: 7843-7848, 2006.

15. Perkins GH, Schomer DF, Fuller GN, Allen PK and Maor MH: Gliomatosis cerebri: improved outcome with radiotherapy. Int J Radiat Oncol Biol Phys 56: 1137-1146, 2003.

16. Sanson M, Cartalat-Carel S, Taillibert S, Napolitano M, Djafari L, Cougnard J, Gervais H, Laigle F, Carpentier A, Mokhtari K, Taillandier L, Chinot O, Duffau H, Honnorat J, Hoang-Xuan K and Delattre JY: Initial chemotherapy in gliomatosis cerebri. Neurology 63: 270-275, 2004.

17. Ross IB, Robitaille Y, Villemure JG and Tampieri D: Diagnosis and management of gliomatosis cerebri: recent trends. Surg Neurol 36: 431-440, 1991.

18. Herrlinger U, Felsberg J, Kuker W, Bornemann A, Plasswilm L, Knobbe CB, Strik H, Wick W, Meyermann R, Dichgans J, Bamberg M, Reifenberger G and Weller M: Gliomatosis cerebri: molecular pathology and clinical course. Ann Neurol 52: 390-399, 2002.

19. Kim DG, Yang HJ, Park IA, Chi JG, Jung HW, Han DH, Choi KS and Cho BK: Gliomatosis cerebri: clinical features, treatment, and prognosis. Acta Neurochir (Wien) 140: 755-762, 1998.

20. Suzuki T, Izumoto S, Wada K, Fujimoto Y, Maruno M, Yamasaki M, Kanemura Y, Shimazaki T, Okano H and Yoshimine T: Inhibition of glioma cell proliferation by neural stem cell factor. J Neurooncol 74: 233-239, 2005.

21. Vates GE, Chang S, Lamborn KR, Prados M and Berger MS: Gliomatosis cerebri: a review of 22 cases. Neurosurgery 53: 261-271, 2003.

22. Levin N, Gomori JM and Siegal T: Chemotherapy as initial treatment in gliomatosis cerebri: results with temozolomide. Neurology 63: 354-356, 2004.

23. Burns MJ and Weiss W: Targeted therapy of brain tumors utilizing neural stem and progenitor cells. Front Biosci 8: e228-e234, 2003.

24. Sanai N, Alvarez-Buylla A and Berger MS: Neural stem cells and the origin of gliomas. N Engl J Med 353: 811-822, 2005.

25. Hellstrom M, Kalen M, Lindahl P, Abramsson A and Betsholtz C: Role of PDGF-B and PDGFR-beta in recruitment of vascular smooth muscle cells and pericytes during embryonic blood vessel formation in the mouse. Development 126: 3047-3055, 1999.

26. Kesari S and Stiles CD: The bad seed: PDGF receptors link adult neural progenitors to glioma stem cells. Neuron 51: 151-153, 2006.

27. Jackson EL, Garcia-Verdugo JM, Gil-Perotin S, Roy M, Quinones-Hinojosa A, VandenBerg S and Alvarez-Buylla A: PDGFR alpha-positive B cells are neural stem cells in the adult SVZ that form glioma-like growths in response to increased PDGF signaling. Neuron 51: 187-199, 2006.

28. Dai C, Celestino JC, Okada Y, Louis DN, Fuller GN and Holland EC: PDGF autocrine stimulation dedifferentiates cultured astrocytes and induces oligodendrogliomas and oligoastrocytomas from neural progenitors and astrocytes in vivo. Genes Dev 15: 1913-1925, 2001. 